\title{
A Comparison of Business Case and Engineering Design Case Structures
}

\author{
Oscar Nespoli, Andrea Hagedorn, Colin Campbell, and Stephan Lambert
}

\begin{abstract}
The structure of cases used in the teaching and learning of business management knowledge and cases being developed for the teaching and learning of engineering design knowledge are compared. General similarities are found that parallel a systematic problem solving process. Differences exist in terminology and the grouping of process stages.
\end{abstract}

Index Terms - Cases, case method, engineering design, design methodology, engineering education

\section{INTRODUCTION}

$\mathrm{T}$ he University of Waterloo (UW) is a co-operative engineering school where students are required to gain practical engineering experience between each academic term. Over one thousand (1000) work term reports, capturing this experience, are submitted at the end of each term of four (4) months. A group has been established to enhance engineering design education by developing some of these work term reports into engineering design cases, and implementing them into the curriculum faculty-wide. The group is also active in obtaining engineering design case materials from industry partners, and supports a Master of Engineering (MEng) certificate in design specialization program for the department of Mechanical and Mechatronics Engineering.

A study comparing traditional business cases with engineering design cases has been undertaken to understand how best to structure engineering design cases for use in teaching of engineering design and design methodology. The primary question to be answered is what is the difference between a traditional business case structure and engineering

Manuscript received June 16, 2008. This work was supported in part by the National Sciences and Engineering Research Council (NSERC), and General Motors of Canada Limited (GMCL).

O. G. Nespoli is with the Waterloo Cases in Design Engineering (WCDE) group, Department of Mechanical and Mechatronics Engineering, University of Waterloo, Waterloo, Ontario, Canada, N2L 3G1 (phone: 519-888-4420; fax 519-885-5862; e-mail: oscar@ design.uwaterloo.ca).

A. Hagedorn is with the Waterloo Cases in Design Engineering (WCDE) group, Department of Mechanical and Mechatronics Engineering, University of Waterloo, Waterloo, Ontario, Canada, N2L 3G1 (e-mail: andrea@design.uwaterloo.ca).

C. G. W. A. Campbell is with the Waterloo Cases in Design Engineering (WCDE) group, Department of Mechanical and Mechatronics Engineering, University of Waterloo, Waterloo, Ontario, Canada, N2L 3G1 (e-mail: campbell@design.uwaterloo.ca ).

S. B. Lambert is Chair of the Waterloo Cases in Design Engineering (WCDE) group, Department of Mechanical and Mechatronics Engineering, University of Waterloo, Waterloo, Ontario, Canada, N2L 3G1 (e-mail: steve@design.uwaterloo.ca ). design cases currently being developed at the University of Waterloo?

The capability to design and create is a distinguishing mark of engineering [1]. It is recognized that enhancing this capability has the potential to contribute much to the social and economic welfare of society. However, engineering design is difficult to learn and difficult to teach. Design practice knowledge is difficult to capture and express in a traditional classroom setting. Higher order skills, such as working as an effective team member, managing uncertainty and complexity, presentation and interpersonal communication skills, application of project management tools and techniques are important aspects of a successful engineering design endeavor, and best learned in an active, as opposed to a passive setting.

Cases, and more specifically the case method, offer a proven mechanism for capturing real experiences, and delivering these experiences using carefully designed document-based products, while using existing university classrooms and facilities. Carefully crafted cases can integrate concepts and practical knowledge in a situational context, be motivating for the students and promote a systematic approach to solving engineering design problems and opportunities.

Engineering case histories are important accounts of major failures and are well documented, while case studies demonstrate ideal or benchmark solutions [2]. Engineering design cases being developed at UW are not limited to accounts of spectacular failures or ethics in engineering management, but focus on case studies and case problems, where a specific design challenge was overcome.

The purpose of this paper is to examine how a business case is structured relative to engineering design cases currently under development at UW, and whether this assessment can lead to a better understanding of cases and the case method for the teaching and learning of engineering design.

\section{Business CASE StruCture}

\section{A. Case Difficulty Dimensions}

The Ivey School of Business has developed a framework for categorizing the difficulty of the cases they develop. This framework, known as the Case Difficulty Cube, is comprised of three dimensions; the analytical dimension, the conceptual dimension and the presentation dimension. The rating along the analytical dimension indicates what is expected from the case reader, with respect to analyzing the key decision or issue presented in the case, the rating along the conceptual dimension indicates the breadth and depth of the concepts 
required to develop a solution for the case and the rating along the presentation dimension indicates the degree of sorting and structuring of information required by the reader. According to the Case Difficulty Cube framework, each case may be given a score of one, two or three along each of the dimensions, yielding a total of 27 independent case classifications. A summary of each difficulty level for each dimension of the framework is presented in Table I.

TABLE I

CASE DIFFICULTY DIMENSIONS

\begin{tabular}{|c|c|c|}
\hline Dimension & $\begin{array}{l}\text { Difficulty } \\
\text { Level }\end{array}$ & Business Case \\
\hline \multirow{3}{*}{ Analytical } & 1 & Evaluate a decision already made. \\
\hline & 2 & Assess an issue, decision or opportunity. \\
\hline & 3 & Identify problems, issues and challenges. \\
\hline \multirow[t]{3}{*}{ Conceptual } & 1 & $\begin{array}{l}\text { Solved using a single concept covered in } \\
\text { readings, without additional explanation in } \\
\text { class }\end{array}$ \\
\hline & 2 & $\begin{array}{l}\text { Solved using several simple concepts or a } \\
\text { single complex concept with some } \\
\text { explanation or further discussion in class. }\end{array}$ \\
\hline & 3 & $\begin{array}{l}\text { Solved using a variety of concepts with } \\
\text { substantial assistance and explanation given } \\
\text { in class. }\end{array}$ \\
\hline \multirow[t]{3}{*}{ Presentation } & 1 & $\begin{array}{l}\text { Short, well organized, no extraneous } \\
\text { information, little missing information. }\end{array}$ \\
\hline & 2 & $\begin{array}{l}\text { Medium length, some disorganization, some } \\
\text { extraneous information, some missing } \\
\text { information. }\end{array}$ \\
\hline & 3 & $\begin{array}{l}\text { Long, disorganized, lots of extraneous } \\
\text { information, lots of missing information. }\end{array}$ \\
\hline
\end{tabular}

\section{B. Case Structure by Subtitles}

Separate from the framework outlined above, the Ivey Business School suggests that the structure of a business case contains the key subtitles shown in Table II.

TABLE II

BUSINESS CASE STRUCTURE BY SUBTITLES [3]

\begin{tabular}{ll}
\hline \hline & \multicolumn{1}{c}{ Business Case Structure } \\
\hline 1 & The Opening Paragraph \\
2 & General Company Background \\
3 & Specific Area of Interest \\
4 & Specific Problem or Decision \\
5 & Alternatives (optional) \\
6 & Conclusion \\
7 & Exhibits \\
\hline
\end{tabular}

The case begins with an opening paragraph, or a lens into the case, with remaining sections gradually focusing the reader from general background and contextual information to details regarding the business situation at hand.

The opening paragraph is designed to be a very concise introduction that summarizes the case and the situation. This section typically describes a so called trigger, or an event that a protagonist is required to deal with.

The next section describes the company background and perhaps the external industry environment as well. This is further refined in section 3 to describe the specific company function of concern, the situation details, and the protagonist job responsibilities.
The heart of the case is section 4 . This section describes the issue, decision or opportunity facing the protagonist. The case concludes with a question. The reader is asked to place themselves in the position of the protagonist, perform an analysis, come to a well-considered decision, and finally recommend implementation plans that can be justified in front of his/her peers.

Exhibits are often provided to support the case situational description, or in cases with higher presentation level of difficulty, are designed to deliberately provide extraneous information.

\section{Case Structure Using the Decision Frame}

The Ivey Business School also describes a so called decision frame, as part of case structure. It is described as an element of case design, whereby the writer would cut the decision frame depending on the learning objectives of the case. We have found it is useful to include this decision frame as part of the case structure described above. This is shown in Table III.

TABLE III

BUSINESS CASE STRUCTURE WITH THE DECISION FRAME INCLUDED [3]

\begin{tabular}{ll}
\hline \hline & \multicolumn{1}{c}{ Business Case Structure } \\
\hline 1 & The Opening Paragraph \\
2 & General Company Background \\
3 & Specific Area of Interest \\
4 & Specific Problem or Decision \\
& - Issue not identified \\
& - Awareness and information gathering \\
& - Analysis \\
5 & - Alternative generation \\
& - Decision \\
& - Implementation \\
& Concluation \\
7 & Exhibits \\
\hline
\end{tabular}

This reflects structure in the analytical dimension. A difficult analytical case would be cut at an earlier point in the decision frame, forcing the reader to identify the issue(s) at hand and come to a decision. A less difficult case would present a decision taken by a protagonist, and ask the reader to evaluate this decision and generate implementation plans to support it.

\section{ENGINEERING DeSign CASE StRUCture}

The engineering design process can be expressed and described in many ways [4], but we find that a convenient description of this process is provided in Table IV below.

TABLE IV

THE ENGINEERING DESIGN PROCESS [5]

Engineering Design Process

\begin{tabular}{ll}
\hline 1 & Need Analysis \\
2 & Conceptual Design \\
3 & Embodiment Design \\
4 & Detailed Design \\
5 & Prototype Creation \\
\hline
\end{tabular}


The process begins with a need analysis phase, where a need is recognized, but not necessarily fully understood. Understanding is developed through background research and evaluation of the current state-of-the-art. This culminates with the real need, or needs, identified fully. This is simple to state in words, but very difficult to do well in practice. The identified needs are classified in terms of functional requirements, and finally expressed as detailed and quantified design specifications. These specifications are communicated in a form that is accepted and understood. This ends the problem finding and defining phase.

The next phase is concerned with generating ideas and solutions to meet the stated problem and opportunity, and includes assessing each concept, and finally selecting one or more to develop in further detail.

Implementation of the selected concept follows with increasing levels of design refinement with embodiment design and detailed design. The design is verified through both analysis and test involving a physical artifact or prototype.

Many models of this process exist [4], but all follow this general process. This is presented sequentially here, however it is recognized that this is often an iterative activity.

\section{COMPARISON}

We find a parallel between this problem solving process, and the analysis process defined in business cases. We see an opportunity to compare these processes, and the business case structure above to propose a potentially useful structure for engineering design cases. This is summarized in Table $\mathrm{V}$ and discussed further below.

TABLE V

Business CASE AND ENGINEERING DESIGN CASE COMPARISON

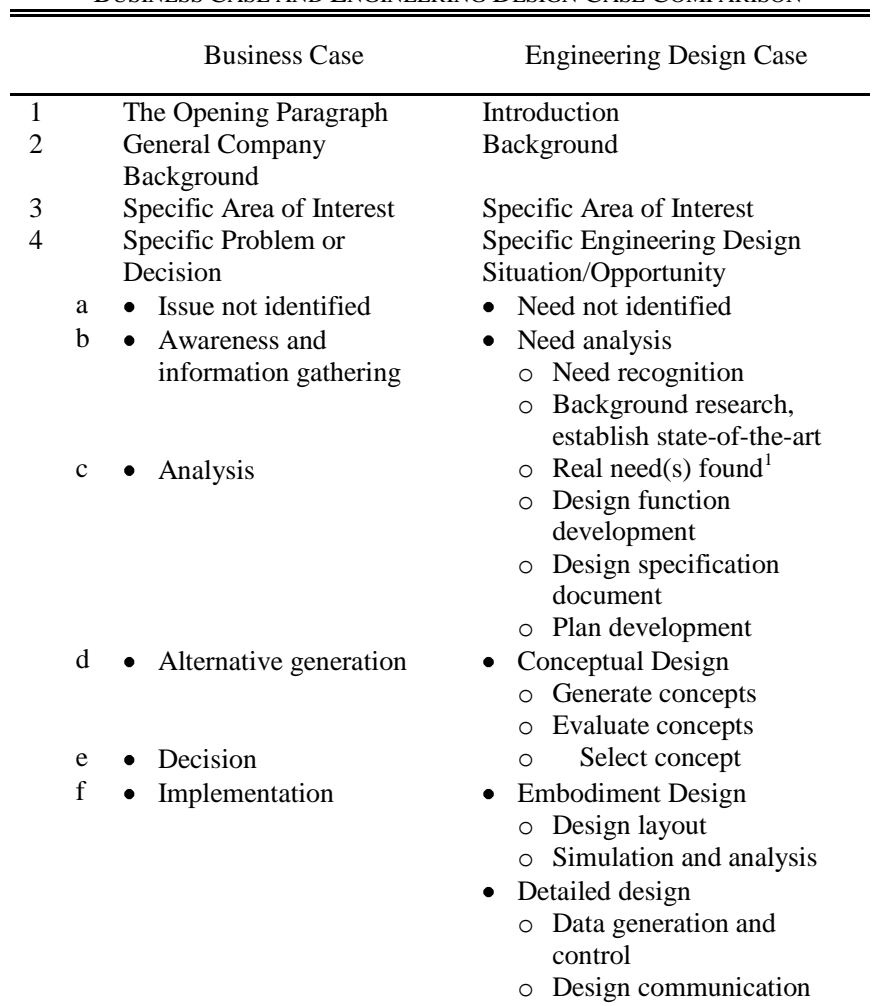

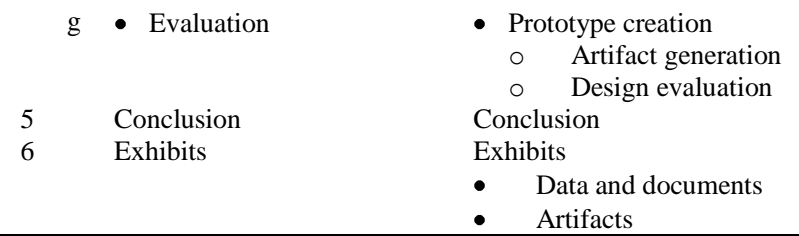

${ }^{1}$ This is a very important and often under-emphasized part of the engineering design process.

In order to introduce the case to the reader, it is important to provide an introduction, similar to the opening paragraph. Company background and the specific area of interest focus the context of the case for the analysis to follow. For engineering cases, this may also include the treatment of conceptual and technical information, perhaps as an appendix or a separate module. Nevertheless, the goal of this section is to situate the reader for the learning and analysis to follow.

Section 4 in Table $\mathrm{V}$ introduces the specific decision, problem or opportunity for a business case. This section represents the decision frame, and the case will be cut at one of the sub-sections in section 4 , depending on the learning objectives required. The case concludes with the presentation of a question, i.e. what would you do if you were in his/her position and why? Learning with cases requires that the students study the case individually, in groups, and finally as a class. Learning is then developed through questioning and discussion.

When the engineering design process is placed against the business case decision process we see parallels in the progression of problem solving, but differences in terminology and grouping of the various stages.

Both processes begin with issues and design needs not identified. One finds that this is in fact an important step to move through in practice, seeing the issues and opportunities for resolving deficiencies in the environment. Cases cut at this level would be challenging indeed, as they represent exercises in problem finding rather than problem solving.

Step $4 \mathrm{~b}$, awareness and information gathering compares with need recognition and gathering of background information. The goal of these activities is to reach the essence of the problem, sometimes referred to as the root cause in engineering re-design activities related to quality continuous improvement.

Step $4 \mathrm{c}$ is the analysis portion of a business case and we find that this compares well with identifying the real problem or the real need. In an engineering case this would also require defining the need in terms of functional requirements, and communicating these requirements in the form of a detailed design specification. In both the business case and engineering design case sections, this should complete the problem finding and defining phase.

Section $4 \mathrm{~d}$ is concerned with developing alternatives and solutions to the stated issues and needs. Concepts are generated and evaluated.

The decision step compares with the concept selection step, 4e. From this point, implementation plans are put in place to clarify the concept, and embody it, making it more detailed. As it is made more detailed, simulation and analyses are conducted to determine its feasibility. Changes are made as 
required by iteration. Similarly business plans are generated in more detail at this step.

The evaluation step is concerned with verifying the embodied engineering concept, and this may be performed by creating a physical artifact of the design, or by conducting analyses to demonstrate functional performance. Typically a design will need to be revised somewhat, requiring re-design at some previous step in the process.

The exhibits are important elements of a case, and both would contain important data to supporting the background of the case. We see an opportunity to include hardware artifacts in some engineering cases, where it is feasible, to reinforce the evaluating of deficiencies in an existing design.

Where a business case would typically end with a question, and sometimes reveal the course taken by the protagonist and the company, we find it is important to reveal the eventual solution developed in an engineering design case, while recognizing that this may represent one of many acceptable solutions possible.

\section{DISCUSSION}

The result of the comparison above is encouraging, since business cases are proven pedagogical mechanisms. It is recognized, however, that while the structures are similar, ultimate success in imparting learning using cases also depends on how the case is implemented, and how well the case method promotes questioning, discussion and active learning.

A cursory review of the psychology literature on problem solving reveals that both business cases and engineering design cases follow a generally accepted problem solving process [6] - [8].

The problem solver must;

- Recognize or identify the problem

- Define and represent the problem mentally

- Develop a solution strategy

- Organize his or her knowledge of the problem

- Allocate mental and physical resources for solving the problem

- Monitor his/her progress toward the goal

- Evaluate the solution for accuracy

Reference [6] also suggests that two (2) classes of problems exist: those that are considered well-defined and those that are considered ill-defined.

Typically, engineering education emphasizes the problem solving phase, and the author's professional management experience suggests that few engineers have developed the skill to recognize, define and represent a design or re-design situation or opportunity well. We believe that engineering design cases are well suited to address this by focusing learning on both ill-defined problems, and in the problem finding phase of the design process.

Table VII compares the problem solving process of [6] and the engineering design process above.
TABLE VI

ENGINEERING DESIGN CASE AND PROBLEM SOLVING COMPARISON

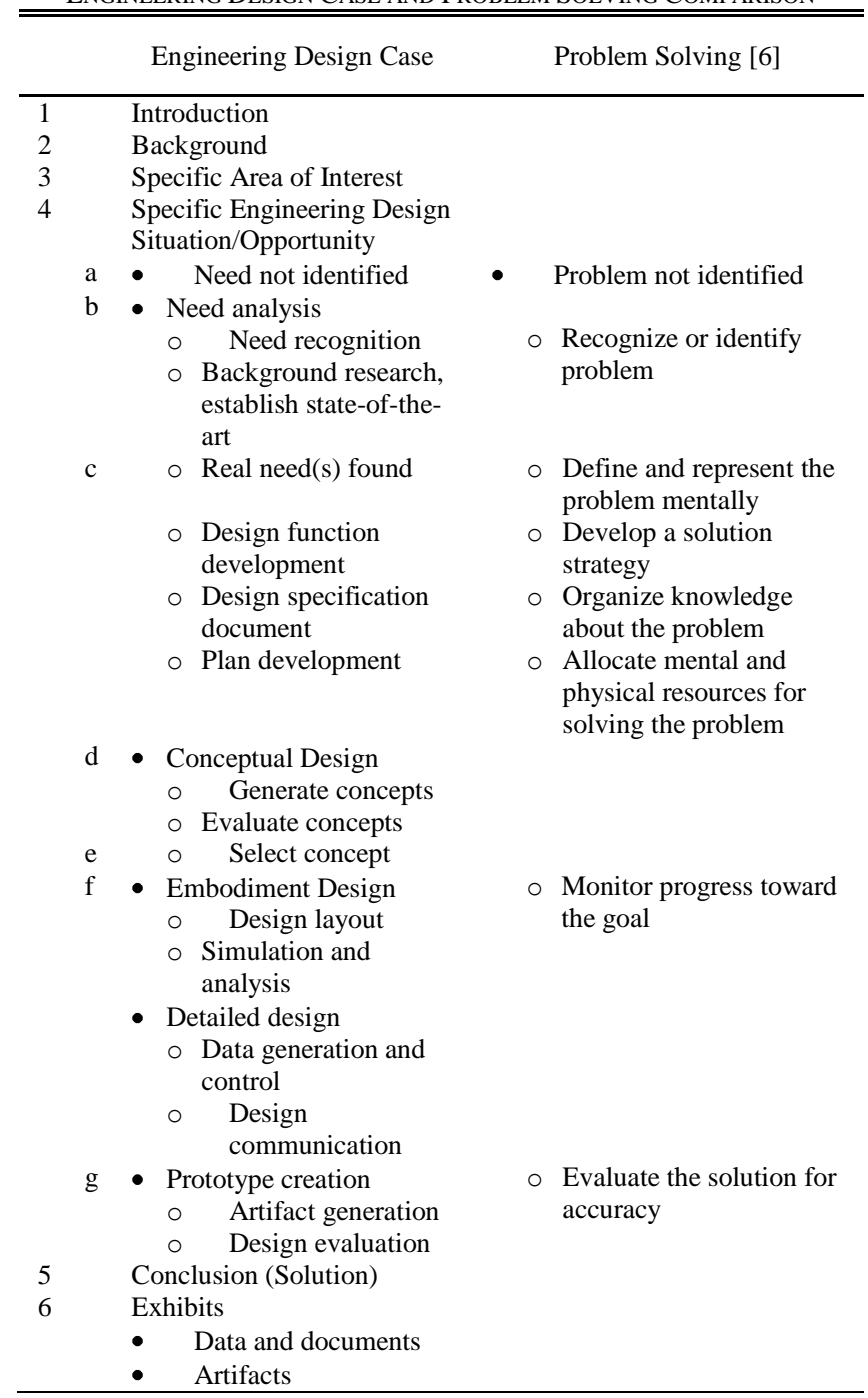

\section{CONCLUSION AND RECOMMENDATIONS}

Our study comparing the structure of business cases and engineering design cases being developed at UW indicate that there are similarities in the analytical dimension. Similarities also exist in the case structure, where the reader is introduced to the situation, and provided background context and exhibits in order to be put in a position to assess and make recommendations. Engineering design cases will contain background to support the theoretical concepts and provide technical information for the reader was well.

Differences exist in terminology at each stage, and in the grouping of the steps within each stage (i.e. information gathering and analysis versus need analysis).

A cursory review of the psychology literature on problem solving suggests that both business case and engineering design case structures follow a generally accepted process for problem finding and solving.

While we do not yet have pervasive experience in implementing engineering design cases, we have always concluded the delivery of engineering design cases by divulging the student's design solution. We view it important 
to offer the case solution as closure to the case. Business cases may or may not conclude with the presentation of the firm's actual solution to the problem, but the final outcome is often accessible to both instructors and students through information that is available in the public domain. The solution to engineering design cases derived from work reports however is not likely to become publically available; therefore the student's solution to the engineering design case is made available to the instructor who may choose to share the solution with students in the classroom.

Further experience using engineering design cases is required to fully assess the effectiveness of the proposed structure; however the strong parallels in structure with proven business cases indicate that effectively implementing such cases could produce very promising results.

\section{REFERENCES}

[1] H.A Simon HA, The Sciences of the Artificial, Cambridge MA: MIT Press, 1996, ch. 5.

[2] L. G. Richards, and M. E. Gorman, "Using Case Studies to Teach Engineering Design and Ethics", Proceedings of the 2004 American Society for Engineering Education Annual Conference and Exposition.

[3] M. R. Leenders, L. A. Maufette-Leenders, and J. A. Erskine, Writing Cases, London ON Canada: Richard Ivey School of Business, 2001.

[4] T. Howard, S. Culley, and E. Dekoninck, "Creativity in the Engineering Design Process", International Conference on Engineering Design (ICED) 07, Paris, 2007.

[5] S. S. Karuppoor, C. P. Burger, and C. Ravinder, "Designing Better", Proceedings of the 2002 ASEE Gulf-Southwest Annual Conference, American Society for Engineering Education (ASEE), 2002.

[6] J. E. Pretz, A. J. Naples, and R. J. Sternberg, "Recognizing, Defining and Representing Problems", in The Psychology of Problem Solving, J. E. Davidson, and R. J. Sternberg, Ed., Cambridge MA: Cambridge University Press, 2003, pp. 3-30.

[7] R. J. Sternberg, Beyond IQ: A Triarchic Theory of Human Intelligence, Cambridge MA: Cambridge University Press, 1985.

[8] R. J. Sternberg, "A Balance Theory of Wisdom", Review of General Psychology, Vol. 2, No. 4, pp. 347-365, 1998. 